\title{
OBITUARY
}

\section{In memoriam: Rubem Lederman}

Published online: 15 May 2012

(C) International Osteoporosis Foundation and National Osteoporosis Foundation 2012

The International Osteoporosis Foundation (IOF) and its members were deeply saddened to learn of the death of Professor Rubem Lederman on April 16, 2012 at the age of 76. Rubem was a long-serving IOF Board Member from 1999 to March 2012. He will be greatly missed and warmly remembered as a valued friend and supporter of IOF. His important accomplishments in education, training and public advocacy will continue to serve the cause of osteoporosis patients in Brazil and in the Latin American region.

Colleague and friend, Professor Christiano Zerbini, said, "Brazilian rheumatologists are very sad as we have lost a very good and beloved friend. Rubem was an excellent person and a wonderful colleague. As a director of the Brazilian Society of Rheumatology he worked hard to bring together all the country's regions. Rubem was always concerned with the participation of all Brazilian rheumatologists in the Society's life and took a lot of care not to exclude anyone. We will miss him... Rubem will stay in the annals of the Brazilian Society of Rheumatology but, mostly, in the heart of his friends."

Rubem Lederman was Chief of the Rheumatology Dept. and Clinical Research Chief of the Hospital dos Servidores do Estado do Rio de Janeiro. He was Founder and President of the Brazilian Osteoporosis Society, Co-founder of FENAPCO, and was President of the Brazilian Society of Rheumatology from 1982 to 1984 and of the Brazilian Academy of Rheumatology from 1994 to 1996. He was also President of the AntiAgeing Society and the International Ibero-American Committee from 1994 to 1998. Rubem was well known in Latin America and was an honorary member of the Argentine and Chilean Rheumatology Societies. He was Co-chair of the 2004 IOF World Congress on Osteoporosis in Rio de Janeiro and Executive President of the XVII World Rheumatology Congress ILAR held in Brazil in 1989. 